\title{
Toluene diisocyanate induced asthma: outcome according to persistence or cessation of exposure
}

\author{
Giorgio Pisati, Adriana Baruffini, Sergio Zedda
}

\begin{abstract}
Sixty patients with occupational asthma due to exposure to toluene diisocyanate (TDI) were re-evaluated, five years after the initial diagnosis had been confirmed by a specific bronchial provocation challenge. During both examinations the severity of asthmatic symptoms and the need for antiasthma treatment were graded and lung function tests, measurement of airway responsiveness to methacholine $\left(P D_{15}\right)$, and skin tests with common inhalant allergens were carried out. The evolution of the disease was established on the basis of the increase or decrease in asthmatic symptoms, requirements for medication, and $F E V_{1}$ and $\mathbf{P D}_{15}$ methacholine between the two examinations. At follow up 17 patients (group A, 28.3\%) had carried on working in the same environment after relocation to jobs with only occasional exposure to TDI; 15 of them used protective respiratory devices. The remaining 43 (group $B, 71 \cdot 7 \%$ ) avoided further inhalation of TDI by moving to another sector. Group A showed a significant decrease in $F E V_{1}$ and $P D_{15}$ methacholine and significant increases in the severity of symptom score and requirement for medication; 13 subjects $(76 \cdot 5 \%)$ were worse, four $(23.5 \%)$ were stable, and no one had recovered or improved. Group B showed significantly less severe symptoms and a threefold increase in $\mathbf{P D}_{15}$ methacholine; 12 subjects $(28 \cdot 2 \%)$ totally recovered, $10(23.2 \%) \mathrm{im}-$ proved, $16(37 \cdot 2 \%)$ were stable, and five $(11.6 \%)$ were worse. In group $B$ the duration of exposure to TDI and of symptoms before the initial diagnosis delineated the patients who recovered from those who did not improve; intermediate values in these features characterised the subjects who improved but did not recover. It is inferred that complete removal
\end{abstract}

Associazione dei Comuni del Lecchese, Unità Socio Sanitaria Locale n 16, Lecco, Presidio Ospedaliero di Lecco, Servizio de Medicina del Lavoro, C.50 Promessi Spose 122053 Lecco, Italy G Pisati, A Barruffini, S Zedda from exposure is the only effective way of preventing deterioration in patients with occupational asthma due to TDI. Early diagnosis and early removal from exposure after the onset of asthma are important factors for a favourable outcome of the disease.

\section{(British Journal of Industrial Medicine 1993;50:60-64)}

Isocyanates, particularly toluene diisocyanate (TDI), are the agents responsible for a large proportion of occupational asthma in Italy and have been responsible for about $47 \%$ of the cases of asthma due to occupational sensitisers in the past 10 years. ${ }^{1}$

Several questions remain unanswered regarding the natural course of the disease. One question, vital for its practical implications, is whether in sensitised subjects the reduction of exposure and the use of appropriate medication can be as effective as that of leaving the job in preventing clinical deterioration. Little information is available on this topic as not much is known about TDI induced asthma in patients who decided to carry on working in the same industry..$^{2-5}$ Uncertainty also exists as to the outcome of TDI induced asthma after stopping exposure and as to what factors affect the prognosis. We found eight follow up studies on workers with TDI induced asthma who avoided further exposure to the substance after confirmation of the diagnosis. ${ }^{2-9}$ Recovery was found in a variable proportion of subjects that ranged from $19 \%{ }^{6}$ to $86 \%{ }^{2}$; also the factors affecting the outcome varied considerably. Some authors considered that the persistence of asthma was due to duration of exposure to TDI. ${ }^{4}$ Others attached great importance to the patients' pulmonary condition at diagnosis or to the type of asthmatic reaction to the TDI inhalation challenge. ${ }^{589}$ One study was unable to find any feature, at the time of the diagnosis, that subsequently distinguished the patients who recovered from those who did not. It is likely that part of the difficulty in solving these questions is due to the few subjects evaluated and to the different duration of the follow up, which often ranges from months to years in patients of the same report.

To retrieve more data on the natural history of the disease we performed a follow up study on a con- 
siderable number of workers with asthma due to TDI sensitisation, all of whom were re-evaluated five years after the initial diagnosis had been confirmed by a specific inhalation challenge test; they were representative of the total cases with TDI induced asthma assessed between 1980 and 1985 in our hospital.

\section{Methods}

All 65 patients with TDI induced asthma diagnosed between 1980 and 1985 in our hospital were recalled five years ( \pm 7 months) later; they were informed that re-examination was not to assess disability for compensation but to update the knowledge of their health.

Sixty workers accepted, (five were not traced); 53 of them were spray painters who used polyurethane paints, three produced polyurethane varnishes, three manufactured polyurethane foams, and one soldered electric wires coated with polyurethane resins.

At diagnosis all subjects filled in a questionnaire: information was obtained about the characteristics of the risk of exposure to TDI at the workplace (continuous or intermittent exposure, use of protective respiratory devices, presence of ventilation), the severity of the asthmatic symptoms, need for medication, and stays in hospital for asthma over the past 12 months. Symptoms were graded as grade 0 (no wheezing or chest tightness); grade 1 (occasional episodes of wheezing or chest tightness); grade 2 (weekly episodes of wheezing or chest tightness); grade 3 (daily occurrence of the symptoms); grade 4 (grade 3 plus a stay in hospital). The need for antiasthmatic medication was assessed using the scale: grade 0 (no medication); grade 1 (use of $\beta_{2}$ agonist when necessary); grade 2 (daily use of $\beta_{2}$ agonist); grade 3 (daily use of $\beta_{2}$ agonist and inhaled steroids or systemic methylxanthine preparations); grade 4 (grade 3 plus the use of systemic corticosteroids).

All subjects underwent (1) skin tests with a battery of 15 common inhalant allergens, using the intradermal method; a reaction was considered positive when a weal diameter was at least half of that brought about by a histamine control solution; atopy was regarded as present when one or more positive reactions were elicited. (2) Lung function tests: inspiratory vital capacity (VC) and forced expiratory volume in one second $\left(\mathrm{FEV}_{1}\right)$ were measured according to the recommendations of the European Community for Coal and Steel (ECCS) ${ }^{10}$ with a pneumotachograph instrument (Transferscreen Jaeger, Wurzburg). Subjects were studied in the standing position with nose clips. All subjects had been free of respiratory infections for at least two weeks and had not been exposed to TDI for at least one week. None had taken cromolyn, theophylline, sympathomimetic drugs, or corticosteroids 48 hours before examination. Reference values were those of the ECCS. ${ }^{11}$ Lung function was considered impaired when VC or $\mathrm{FEV}_{1}$ was $<80 \%$ of that predicted; an obstructive type of ventilatory defect was diagnosed when $\mathrm{FEV}_{1}$ was less than $80 \%$ of that predicted and was associated with a reduction in $\mathrm{FEV}_{1} / \mathrm{VC}$. (3) A methacholine inhalation test was performed with a Mefar dosimeter according to the protocols of the Italian Societies of Respiratory Pathophysiology and of Occupational Medicine for non-specific bronchial provocation tests. ${ }^{12}$ Dose response curves to methacholine were obtained by plotting the baseline value for $\mathrm{FEV}_{1}$ and the value after each methacholine dose against the cumulative dose of methacholine delivered, on a log scale; the cumulative dose of methacholine producing a $15 \%$ fall in $\mathrm{FEV}_{1}\left(\mathrm{PD}_{15}\right)$ was calculated by interpolation from the doseresponse curve. A subject was regarded as hyperreactive to methacholine when his $P_{15}$ was $1 \mathrm{mg}$ or less. (4) Inhalation challenge to TDI: the subjects were exposed to 0.02 (SD 0.004) ppm of 2,4-2,6 TDI vapours $(80: 20)$ generated in a $7 \mathrm{~m}^{3}$ exposure chamber by heating $0.035 \mathrm{ml}$ of isocyanate on a watch glass at $60^{\circ} \mathrm{C}$, with a fan in the room. The duration of exposure was up to 20 minutes unless there was an earlier appearance of respiratory symptoms. On the day of the challenge $\mathrm{FEV}_{1}$ was monitored every 15 minutes for one hour before exposure. The largest of the first three technically satisfactory FEV $_{1}$ values was recorded; this was not to be less than $95 \%$ of $\mathrm{FEV}_{1}$ recorded on the day of the baseline lung function study and maximum variations were not to be greater than $5 \%$ to carry on with the test. The $\mathrm{FEV}_{1}$ value assessed immediately before the exposure to TDI was chosen as the baseline $\mathrm{FEV}_{1}$ of the day of the TDI challenge. After the exposure $\mathrm{FEV}_{1}$ was measured at 15,30 , and 60 minutes, then hourly for eight hours, and finally after 24 hours. A challenge test was deemed positive when there was at least a $15 \%$ fall in $\mathrm{FEV}_{1}$ associated with a pattern suggesting sustained bronchial obstruction (sustained fall in $\mathrm{FEV}_{1}$ and wheezing at clinical examination). The asthmatic reactions were classified as early if they developed within 30 minutes after exposure to TDI, late if they developed an hour or more after the exposure, or dual if an immediate reaction was followed by a spontaneous return of $\mathrm{FEV}_{1}$ to the baseline value whereupon a second $F_{E V}$ decrease occurred. ${ }^{13}$

At the follow up examination all patients were questioned about their working conditions since diagnosis (a different job in another industry, the same or different job in the same industry, possible presence of irritant substances for the airways, possible change in the use of protective respiratory devices, or improvement of ventilation at the same workplace). They were also asked about the severity 
of the asthmatic symptoms, the need for asthma medication during the past year, and the occurrence of stays in hospital since the diagnosis. Gradation of symptoms and of medication was done in the same way as at diagnosis. A change in symptom score or medication score by one grade was regarded as significant.

Skin tests for allergy, lung function tests, and bronchial challenge with methacholine were repeated.

A decrement or increment in $\mathrm{FEV}_{1}$ of more than $10 \%$ was regarded as a significant change.

When $\mathbf{P D}_{15}$ methacholine in a patient was at least twofold or half of that recorded at the first examination, this was regarded as a significant change in his bronchial reactivity. Annual loss of $\mathrm{FEV}_{1}$ was also calculated for each subject as:

$$
\frac{\text { Initial } \mathrm{FEV}_{1} \text { value }- \text { final } \mathrm{FEV}_{1} \text { value }}{\text { Months of follow up }} \times 12
$$

A subject was regarded as recovered when he had been symptom and medication free for at least the past 12 months and his lung function tests and airways responsiveness to methacholine were within the normal range; he was regarded as improved or deteriorated if he showed a significant improvement or deterioration in his symptom score or requirement for medication together with a significant improvement or deterioration in the $\mathrm{FEV}_{1}$ baseline value or $\mathrm{PD}_{15}$ methacholine; those who did not fulfil these criteria were considered stable.

\section{STATISTICAL ANALYSIS}

Comparison of ratios was carried out with the $\chi^{2}$ test; comparison of means was by Student's paired and unpaired $t$ tests. The level of statistical significance was set at $p \leqslant 0.01$.

\section{Results}

At the time of the follow up examination, 17 patients (group A, 28.3\%) were still working in the same environment and 43 (group B, $71 \cdot 7 \%$ ) were no longer exposed to TDI because they had moved to another industry.

The comparison of the patients' conditions at diagnosis (table 1) showed that the subjects of group A were older and had had longer exposure to TDI.

Difficulty in finding a new job and the possibility of relocation to an area with discontinuous exposure were the reasons that induced them not to leave their present occupation. At re-evaluation, all 17 patients were assigned to tasks with an only occasional risk of TDI inhalation; all but two regularly used protective respiratory devices (paper masks or twin cartridge respirators); none reported a change in ventilation at the workplace.

Subjects of group B had moved away from exposure within six months after the diagnosis so they had had no inhalation of TDI for about four and a half years when re-examined.

Table 2 reports the clinical data at diagnosis and at follow up in the 60 patients. No patient had changed his smoking habits between the two examinations and the number of atopic patients was the same. The group of subjects with persistent occupational exposure to TDI showed a significant decrease in VC, $\mathrm{FEV}_{1}, \mathrm{FEV}_{1} / \mathrm{VC}$, and $\mathrm{PD}_{15}$ methacholine and a significant increase in the severity of asthmatic symptoms and the need for appropriate treatment (paired $t$ test after five years). Four subjects (23.5\%) were considered stable, $13(76.5 \%)$ had deteriorated, and none had improved or recovered.

At re-evaluation, the group of workers who had avoided further exposure had significantly less severe symptoms and a threefold increase in $\mathrm{PD}_{15}$ methacholine than at diagnosis (paired $t$ test). Twelve subjects $(28 \%)$ had completely recovered, 10 $(23.2 \%)$ had improved but still required treatment for asthmatic symptoms, $16(37 \cdot 2 \%)$ were stable, and five $(11.6 \%)$ were worse.

Although the symptoms score, medication score, lung function tests, and $\mathrm{PD}_{15}$ methacholine of group

Table 1 Characteristics of 60 subjects with TDI induced asthma at the time of diagnosis according to persistence or cessation of exposure at follow up examination

\begin{tabular}{|c|c|c|}
\hline Characteristics & $\begin{array}{l}\text { Group } A(n=17) \\
\text { Still exposed }\end{array}$ & $\begin{array}{l}\text { Group } B(n=43) \\
\text { No longer exposed }\end{array}$ \\
\hline $\begin{array}{l}\text { Age (y) } \\
\text { Smoking habit: }\end{array}$ & $43.6(\operatorname{SD~} 9)^{\star}$ & $34.8(\operatorname{SD~} 12.5)$ \\
\hline Smokers & $3(17 \cdot 6 \%)$ & $6(13.9 \%)$ \\
\hline Non-smokers & $14(82 \cdot 4 \%)$ & $37(86 \cdot 1 \%)$ \\
\hline Atopic state & $2(11.7 \%)$ & $6(13.9 \%)$ \\
\hline Subjects with symptoms of asthma before exposure to TDI & $1(5.9 \%)$ & $2(4 \cdot 6 \%)$ \\
\hline Duration of exposure to TDI $(y)$ & $25(\text { SD } 7 \cdot 9)^{\star \star \star}$ & $11.5($ SD 9.5$)$ \\
\hline Duration of symptoms before diagnosis (y) & $6 \cdot 3($ SD $4 \cdot 7)$ & 3.7 (SD 3.5) \\
\hline \multicolumn{3}{|l|}{ Type of asthmatic reaction induced by TDI challenge: } \\
\hline Immediate & $9(53 \%)$ & $12(28 \%)$ \\
\hline Dual & $4(23.5 \%)$ & $11(25.5 \%)$ \\
\hline Late & $4(23.5 \%)$ & $20[46.5 \%)$ \\
\hline
\end{tabular}


Table 2 Clinical details of 60 patients at diagnosis and at follow up

\begin{tabular}{|c|c|c|}
\hline Characteristics & $\begin{array}{l}\text { Group } A(n=17) \\
\text { Still exposed } \\
\text { Mean }(S D)\end{array}$ & $\begin{array}{l}\text { Group } B(n=43) \\
\text { No longer exposed } \\
\text { Mean }(S D)\end{array}$ \\
\hline $\begin{array}{l}\text { Symptom score: } \\
\text { At diagnosis } \\
\text { At follow up }\end{array}$ & $\begin{array}{l}1 \cdot 7(0 \cdot 8) \\
2 \cdot 3+(1 \cdot 1)^{\star \star \star}\end{array}$ & $\begin{array}{l}1 \cdot 8(0 \cdot 8) \\
0.9+t+(0.8)\end{array}$ \\
\hline $\begin{array}{l}\text { Medication score: } \\
\text { At diagnosis } \\
\text { At follow up }\end{array}$ & $\begin{array}{l}1 \cdot 4(1) \\
2 \cdot 8++\dagger(1)^{\star \star \star}\end{array}$ & $\begin{array}{l}1 \cdot 1(0 \cdot 7) \\
0.9(1 \cdot 2)\end{array}$ \\
\hline $\begin{array}{l}\text { VC (\% predicted): } \\
\text { At diagnosis } \\
\text { At follow up }\end{array}$ & $\begin{array}{l}98 \cdot 1(14 \cdot 2) \\
89 \cdot 2++(10 \cdot 6)\end{array}$ & $\begin{array}{l}98 \cdot 3(12) \\
96 \cdot 7(15 \cdot 6)\end{array}$ \\
\hline $\begin{array}{l}\left.\text { FEV }_{1} \text { (\% predicted }\right) \\
\text { At diagnosis } \\
\text { At follow up }\end{array}$ & $\begin{array}{l}86 \cdot 8(22 \cdot 5) \\
72 \cdot 9++(19 \cdot 4)^{\star \star}\end{array}$ & $\begin{array}{l}92 \cdot 7(16.5) \\
91.9(20 \cdot 8)\end{array}$ \\
\hline $\begin{array}{l}\mathrm{FEV}_{1} / \mathrm{VC}: \\
\text { At diagnosis } \\
\text { At follow up }\end{array}$ & $\begin{array}{l}66 \cdot 4(11 \cdot 7) \\
60 \cdot 1+(13 \cdot 5)^{\star \star}\end{array}$ & $\begin{array}{l}73.5(10 \cdot 7) \\
72.9(13.5)\end{array}$ \\
\hline $\begin{array}{l}\mathrm{PD}_{15} \text { methacholine }(\mu \mathrm{g}) \text { : } \\
\text { At diagnosis } \\
\text { At follow up }\end{array}$ & $\begin{array}{l}425(608) \\
301+++(610)^{\star \star \star}\end{array}$ & $\begin{array}{l}498(357) \\
1617++\dagger(1567)\end{array}$ \\
\hline
\end{tabular}

$A$ and $B$ were similar at the time of the diagnosis they became significantly different at follow up (unpaired $t$ tests). The rate of decline of FEV 1 was 120 (SD 128 $\mathrm{ml} / \mathrm{y}$ ) in patients of group $A$ and 12 (SD 88) $\mathrm{ml} / \mathrm{y}$ in group B; again the difference was significant on unpaired $t$ test analysis. To find out what factors affected the prognosis of the TDI induced asthma in subjects who had left their workplace, group B was divided into three subsets according to the clinical outcome (group I, recovered; group II, improved; group III, not improved-that is, stable plus deteriorated) and their initial data were compared (table 3). Irritant factors for the airways (dusts, fumes or gases) were present in the new workplace in one of the $12(8.3 \%)$ subjects who had recovered, in four of the $10(40 \%)$ patients who had improved, and in five of the $21(23.8 \%)$ who had not improved; the ratios were not statistically different on $\chi^{2}$ analysis. The duration of exposure to TDI and of symptomatic work was significantly shorter in patients who had recovered than in those who had not improved at all; intermediate values characterised the subjects who had improved but had not completely recovered. None of the workers who recovered had had occupational exposure to TDI longer than 10 years and a duration of exposure after the onset of asthmatic symptoms longer than three years.

It was not possible to analyse group $A$ the same way as group B as there were no recovered patients and too few who had improved.

\section{Discussion}

In this study we examined the characteristic features of 60 patients with occupational asthma due to TDI five years after the initial diagnosis according to the persistence or not of exposure to the offending agent.

We found that in most of the group who had decided to continue working in the same environment, relocation to a job with discontinuous exposure, the use of protective devices, or treatment were unable to prevent the worsening of asthmatic symptoms and further damage to the airways. In particular, the yearly loss in $\mathrm{FEV}_{1}$ was about fourfold in these patients compared with normal subjects ${ }^{10}$ and double that seen in patients with nonoccupational asthma. ${ }^{14}$ Similar results were described by Innocenti et al, ${ }^{2}$ Paggiaro et al, ${ }^{3}$ Rosenberg et $a l,{ }^{4}$ and Mapp et $a l^{5}$ in the specific case of workers with TDI induced asthma and by Chan-Yeung et $a l^{15}$ and Cote $e t a^{16}$ in cases of workers continuously exposed to western red cedar.

Table 3 Characteristics of 43 subjects who moved away from exposure to TDI after diagnosis, according to their outcome at the time of follow up examination

\begin{tabular}{|c|c|c|c|}
\hline & $\begin{array}{l}\text { Recovered subjects } \\
\text { (Group } I, n=12 \text { ) }\end{array}$ & $\begin{array}{l}\text { Improved subjects } \\
(\text { Group } I I, n=10)\end{array}$ & $\begin{array}{l}\text { Non-improved subjects } \\
\text { (Group III, } n=21 \text { ) }\end{array}$ \\
\hline Age (y) & $29(11 \cdot 4)$ & $33(12 \cdot 1)$ & $38 \cdot 9(12 \cdot 4)$ \\
\hline \multicolumn{4}{|l|}{ Smoking habit: } \\
\hline Smokers & $2(16 \cdot 7 \%)$ & $1(10 \%)$ & $5(23.8 \%)$ \\
\hline Non-smokers & $10(85 \cdot 3 \%)$ & $9(90 \%)$ & $16(76 \cdot 2 \%)$ \\
\hline Atopic state & 0 & $2(20 \%)$ & $4(19 \%)$ \\
\hline Subjects with symptoms of asthma before exposure to TDI & 0 & 0 & $2(9.5 \%)$ \\
\hline Duration of exposure to TDI (y) & $6 \cdot 3(4 \cdot 1)^{\star}$ & $10(7 \cdot 4)$ & $15 \cdot 9(11 \cdot 1)$ \\
\hline Duration of symptoms before diagnosis $(y)$ & $1 \cdot 6(1 \cdot 2)^{\star \star}$ & $2 \cdot 8(1 \cdot 9)$ & $5.4(3.9)$ \\
\hline Symptom score & $1.9(0.8)$ & $1.9(0 \cdot 7)$ & $1.9(0.9)$ \\
\hline Medication score & $1(0 \cdot 8)$ & $1 \cdot 2(0 \cdot 6)$ & $1 \cdot 2(0 \cdot 6)$ \\
\hline $\mathrm{FEV}_{1}$ (\% predicted) & $92 \cdot 5(14 \cdot 7)$ & $90 \cdot 1(14 \cdot 8)$ & $94(17 \cdot 7)$ \\
\hline $\mathrm{PD}_{15}$ methacholine $(\mu \mathrm{g})$ & $646(390)$ & $478(364)$ & $424(304)$ \\
\hline \multicolumn{4}{|l|}{ Type of asthmatic reaction induced by TDI challenge: } \\
\hline Immediate & $4(33 \cdot 3 \%)$ & $2(20 \%)$ & $6(28 \cdot 5 \%)$ \\
\hline Dual & $2(16 \cdot 7 \%)$ & $3(30 \%)$ & $6(28 \cdot 5 \%)$ \\
\hline Late & $6(50 \%)$ & $5(50 \%)$ & $9(43 \%)$ \\
\hline$\%$ Maximum fall in $\mathrm{FEV}_{1}$ in TDI challenge & $37 \cdot 4(17 \cdot 8)$ & $34 \cdot 5(14 \cdot 3)$ & $37 \cdot 9(16 \cdot 2)$ \\
\hline
\end{tabular}

${ }^{\star} \mathrm{p}<0.01 ;{ }^{\star \star} \mathrm{p}<0.005$ (unpaired $t$ test between groups I and III).

Nos in parentheses are SD unless otherwise stated. 
These findings suggest that complete removal from exposure is the only appropriate way of preventing deterioration in patients with occupational asthma.

This approach does not, however, necessarily lead to recovery. In fact, four years after completely stopping inhalation of TDI, not more than a quarter of the 43 patients were symptom and medication free and had normal lung function tests and airway responsiveness to inhaled methacholine. Roughly another quarter had milder symptoms and had less severe non-specific bronchial hyperreactivity than at diagnosis. We cannot rule out the possibility that asthma will disappear in them with time although it had been shown that a plateau of improvement in workers with occupational asthma is reached about one year after stopping exposure for spirometry, and two years after stopping exposure for bronchial hyperresponsiveness. ${ }^{17}$ Nevertheless, the significant proportion of subjects who had unchanged symptoms of bronchoconstriction and non-specific bronchial hyperreactivity show that asthma due to TDI could give rise to permanent respiratory consequences.

The percentage of our patients still asthmatic at follow up (with the same or milder severity) was comparable with the 41 out of $50(82 \%)$, eight out of $12(66 \%)$, and 27 out of $30(77 \%)$ respectively reported by Lozewicz et al, ${ }^{8}$ Paggiaro et al, ${ }^{3}$ and Mapp et al, ${ }^{5}$ but higher than the 13 out of $50(26 \%)$ and 10 out of $20(50 \%)$ reported by Innocenti et $a l^{2}$ and Rosenberg et al. ${ }^{4}$

As to what factors can affect the prognosis we found that persistence of asthma was associated with the duration of exposure to TDI and of symptoms at work before diagnosis. No other clinical feature at the initial examination delineated improved patients from non-improved patients at follow up. Clinical tests included the degree of non-specific bronchial reactivity and the type and severity of asthmatic reactions induced by the inhalation challenge test to TDI. Also the quality of the new worksite (that is, the amount of non-specific pollutants) did not seem to play a part in the outcome of the disease. These data, in agreement with some of the previous follow up studies on TDI induced asthma after stopping exposure ${ }^{47}$ emphasise the importance of an early diagnosis and early removal from exposure after the onset of asthma for a favourable outcome of the disease, rather than host factors.

1 Sartorelli E, Innocenti A, Mariano A. Epidemiologia dell'asma professionale Atti Congr Internaz Aspetti epidemiologici dell'asma bronchiale. Padova, 7-9 April 1988.

2 Innocenti A, Franzinelli A, Sartorelli E. Studio longitudinale in lavoratori affetti da asma da resine poliuretaniche. Med Lavoro 1981;72:231-7.

3 Paggiaro PL, Loi AM, Rossi B, et al. Follow-up study of patients with respiratory disease due to toluene diisocyanate (TDI). Clinical Allergy 1984;14:463-9.

4 Rosenberg N, Garnier R, Rousselin X, Mertz R, Gervais P. Clinical and socio-professional fate of isocyanate induced asthma. Clinical Allergy 1987;17:55-61.

5 Mapp CE, Chiesura Corona P, De Marzo N, Fabbri L. Persistent asthma due to isocyanates. A follow-up study on subjects with occupational asthma due to toluene diisocyanate (TDI). Am Rev Respir Dis 1988;137:1326-9.

6 Adams WG. Long-term effects on the health of men engaged in the manufacture of toluene diisocyanate. $\mathrm{Br} J$ Ind Med 1975 32:72-8.

7 Hudson P, Cartier A, Pineau RT et al. Follow-up of occupational asthma caused by crab and various agents. J Allergy Clin Immunol 1985;76:682-8.

8 Lozewicz S, Assoufi BK, Hawkins R, Newman Taylor AJ Outcome of asthma by isocyanates. Br J Dis Chest A1987; 81:14-22.

9 Moller D, Brooks S, McKay R, et al. Chronic asthma due to toluene dissocyanate. Chest 1986;90:494-9.

10 European Community for Coal and Steel. Standardised lung function testing. Bulletin Européen de Physiopathologic Respiratoire 1983;19(suppl 5):1-95.

11 Commission des Communates Europeennes (CECA). Tables de references pour les examens spirometriques. Luxembourg: Office des publications officielle de Communautes Europeennes, 1971 .

12 Gruppo di lavoro per la normalizzazione dei testi di provocazione bronchiale aspecifica della Società Italiana di Fisiopatologia Respiratoria e della Società Italiana di Medicina del Lavoro Igiene Industriale Protocollo per l'esecuzione del test di provocazione bronchiale aspecifica. Fisopatologia Respiratoria 1982;3:3-15.

13 Pepys J, Hutchcroft BJ. Bronchial provocation tests in etiologic diagnosis and analysis of asthma. Am Rev Respir Dis 1975 112:829-59.

14 Peat JK, Woolcock AJ, Cullen K. Rate of decline of lung function in subjects with asthma. Eur J Respir Dis 1987, 70:171-9.

15 Chan-Yeung M, Lam S, Koerner S. Clinical features and natura history of occupational asthma due to western red cedar. $\mathrm{Am} \mathrm{J}$ Med 1982;72:411-5.

16 Cote J, Kennedy S, Chan-Yeung M. Outcome of patients with cedar asthma with continuous exposure. Am Rev Respir Dis 1990;141:373-6.

17 Malo JL, Cartier A, Ghezzo H, et al. Patterns of improvement in spirometry, bronchial hyperresponsiveness and specific IgE antibody levels after cessation of exposure in occupational asthma due to snow-crab processing. Am Rev Respir Dis 1988;138:807-12.

Accepted 16 March 1992 